\title{
Chemotherapy-induced mucositis pursuant to different phase of chemotherapy in children with Acute Lymphoblastic Leukemia at Hasan Sadikin Hospital Bandung
}

\author{
Arlette Suzy Puspa Pertiwi \\ Department of Pediatric Dentistry Faculty of Dentistry Universitas Padjadjaran
}

\begin{abstract}
Acute Lymphoblastic Leukemia is the most common Leukemia seen in children. This disease has manifestation in the oral mucosa, which is caused by either the disease itself or its treatment by chemotherapy, such as mucositis. Oral mucositis is one of a common, debilitating complication of cancer chemotherapy. Mucosal toxicity depends on Saveral factors; one of them is the duration of the therapy. The aim of this study is to evaluate chemotherapy-induced mucositis pursuant to different phase of chemotherapy in children with Acute Lymphoblastic Leukemia. Twenty children diagnosed with Acute Lymphoblastic Leukemia who received induction, consolidation, and maintenance chemotherapy of Hasan Sadikin Hospital were included in this study. The criteria used for assessing mucositis was based on general mucositis scale from WHO. Data were collected and presented in the form of tables and percentages. The results showed that every child had developed mucositis during the course of chemotherapy in the induction and consolidation phase, except one child in the maintenance group did not the. at the induction phase $14,3 \%$ had developed mucositis at scale 2 and 86,7 at scale 3 , consolidation phase $50 \%$ at scale 2 and $50 \%$ at scale 1 , and in maintenance phase $14,3 \%$ in scale $28,6 \%$ in scale 1 , and 57,1 in scale 2. Generally, it was concluded that mucositis develops in every phase of chemotherapy but the scale is slighter as the course of chemotherapy enters the advance phases.
\end{abstract}

Key words: Acute Lymphoblastic Leukemia, mucositis phase of chemotherapy

\section{INTRODUCTION}

Acute Lymphoblastic Leukemia (ALL) is a neoplastic disease that occurs from somatic mutation in the progenitor of single lymphoid cell on one of several stages of the development. ${ }^{1} \mathrm{ALL}$ occurs in approximately $80 \%$ of all leukemic cases in children ${ }^{2}$ and constitutes the most common diagnosed malignancy in children under fifteen year-old. Peak incidence occurs in the age group of 2-5 year and affects boys more than girls. ${ }^{1,2}$
One of the treatmentsforALLischemotherapy, besides radiotherapy. Approximately, $75 \%$ children with ALL can survive with chemotherapy, however the therapy may complicate several problems in mucosal health. ${ }^{3}$ Oral mucosa is an area that is the most common affected by chemotherapy since the drugs not only malignant cells, but also influence normal cells with higher division rates such as epithelial cells of the oral mucosa. ${ }^{4}$ Children with higher division rates have great prevalence for this complication. ${ }^{5}$ 
Every chemotherapy drug may induce mucositis. These drugs induce oral ulceration direct and indirectly. Indirectly, the drugs will depress as well and immune response which leads to bacterial, viral, and fungal infections in the oral mucosa. Other drugs may cause oral ulceration directly by interfering the replication and growth of the oral epithelium cells, which disturb the synthesis of the nucleic acid and protein that lead to thinning and ulceration of the mucosa. ${ }^{4}$

Oral mucosa complication which common occurs is mucositis with different level of severity. Mucositis is one of thecommon, debilitating complication of cancer chemotherapy. It causes severe pain and distress, and may limit the tolerance to patiens chemotherapy. Mucositis occurs in the third days after chemotherapy, reaches the peak in the seventh day, and slowly heals in two weeks after cessation of chemotherapy. ${ }^{3}$ Mucosal toxicity which is induced by chemotherapy depends on the antineoplastic drug, therapeutic regimens, and duration of the treatment, dose intensity, and the previous mucosatoxic drugs. ${ }^{4}$

Oral mucosa changes will be seen clinically in the second to the fourth day of chemotherapy. Nonceratine surfaces are the first area that showed the changes with the tendency of erythema and atrophic. Trauma and irritation may increase the desquamate rate and enhance these changes. Epithelium cells which are unable to challenge this desquamate rate well lead to ulceration. ${ }^{5}$

Symptoms of mucositis varied from pain to discomfort that may tolerate the abilities to eat and drink. ${ }^{6}$ This condition may lead to dehydration and malnutrition that reduce the patient's quality of life. Besides that, it constitute a significant risk factor for systemic infection, especially in neutropenic patients. ${ }^{4}$

The aim of this study is to evaluate chemotherapy-induced mucositis pursuant to different phase chemotherapy in children with Acute Lymphoblastic Leukemia.

\section{MATERIAL AND METHOD}

Twenty children aged 4-11 year-old (mean 6,5 year-old) with diagnosis of ALL who received initial induction (7 children), consolidation (6 children), and maintenance $(7$ children) chemotherapy during period of November 2004 to May 2005 in Hasan Sadikin Hospital were included in this study. Every child received the same chemotherapy drugs which consist of methotrexate (intrathecal dose in the first day) and dexamethasone (oral dose $6 \mathrm{mg} / \mathrm{m}^{2} /$ day). No sign of mucosal changes was seen before chemotherapy. Oral examination to seek for mucositis was started one day before chemotherapy up to the seventh day after chemotherapy being initiated. The mucositis scale was recorded based on the most severe level of mucositis in every patient.

The criteria used for assessing the mucositis based on general mucositis scale from WHO which was shown in Table 1. The severity of mucositis is divided into four scales which is determined by its clinical appearance. Table 2 shows the amount of children who develop mucositis after being administered by chemotherapy drugs in three different phases. Every child in induction and consolidation phase develops mucositis and one child in the maintenance group did not develop mucositis. The result also showed that in the the maintenance where the severity or mucositis is slighter than any other groups.

Table 1. General mucositis scale from $\mathrm{WHO}^{5}$

\begin{tabular}{cl}
\hline Scale & \multicolumn{1}{c}{ Clinical appearance } \\
\hline 0 & No mucositis. \\
1 & Erythema with slight burning sensation. \\
2 & $\begin{array}{l}\text { Erythema and ulceration or white patches; oral } \\
\text { pain; patient can eat hard foods. }\end{array}$ \\
& $\begin{array}{l}\text { Erythema and ulceration or white patches; severe } \\
\text { pain, patient is able to eat soft diet. }\end{array}$ \\
& $\begin{array}{l}\text { Erythema and ulceration or white patches; unable } \\
\text { to eat. }\end{array}$ \\
\end{tabular}

Table 2. Percentage of children develop mucositis pursuant to different stage of chemotherapy

\begin{tabular}{ccccccc}
\hline \multirow{2}{*}{$\begin{array}{c}\text { Mucosi- } \\
\text { tis Scale }\end{array}$} & \multicolumn{2}{c}{ Induction } & \multicolumn{2}{c}{ Consolidation } & \multicolumn{2}{c}{ Maintenance } \\
\cline { 2 - 7 } & $\mathrm{n}$ & $\%$ & $\mathrm{n}$ & $\%$ & $\mathrm{n}$ & $\%$ \\
\hline 0 & - & - & - & - & 1 & 14,3 \\
1 & - & - & 3 & 50 & 2 & 28,6 \\
2 & 1 & 14.3 & 3 & 50 & 4 & 57,1 \\
3 & 6 & 85,7 & - & - & - & - \\
4 & - & - & - & - & - & - \\
\hline
\end{tabular}


RESULT

Table 2 shows the amount of children who develop mucositis after being administered by chemotherapy drugs in three different phases. Every child in induction and consolidation phase develops mucositis and one child in maintenance group did not develop mucositis. The result also showed that in the maintenance group the severity or mucositis is slighter than any other groups.

\section{DISCUSSION}

Leukemic children are susceptible to develop oral mucosa disorder that is related to the malignancy and treatment of the disease. One of the most common complication is mucositis which is induced by chemotherapy. ${ }^{7}$

The result of this study showed that chemotherapy as a treatment for ALL may induce complication in oral mucosa called mucositis. Mucositis is an inflammation in the mucous membrane of the mouth which is resulted from the direct cytotoxic effects of chemotherapy drugs in the fast rate of replication of the oral epithelium. It occurs of $40 \%$ patients undergo chemotherapy. ${ }^{7}$

Mucositis development involve direct and indirect mechanisms. Direct effects of cytotoxic drugs on mucosa are interfering the 5 to 14 days of oral epithelium turnover time and inducing an early apoptotic event. Disturbed process of division and maturation of the epithelium cell may seen as thinning, inflammation, and ulcerating of the mucosa. ${ }^{4}$

Overall, nineteen $(95 \%)$ children develop mucositis with different level of severity during the course of chemotherapy not significant to the study carried out by Ramirez-Amador ${ }^{8}$ in Mexico, mucositis occurs only in $24 \%$ of patients. ${ }^{7}$ This difference is due to the intervention before the chemotherapy being initiated. Before chemotherapy, every patient was treated to undergo mouth preparation that consist of dental treatment for teeth which experience abnormalities and instructed to maintan good oral hygiene. In Indonesia, these were not done yet. Most of leukemic children come to the hospital with severe condition of its illness until the chemotherapy must be initiated as soon as possible without paying any attention to patient's oral hygiene level.

Mucositis induced by chemotherapy occurs in the third day after initial chemotherapy and heals one to two weeks after cessation of chemotherapy. At the end of every phase of chemotherapy, patients were due to a recess period for recovery before beginning another phase. Stailing in to that, the mucositis will heal before entering another phase. Mucosal toxicity depends on the experience of previous mucosatoxic drugs and the duration of treatment. The result of this study showed that the severity of mucositis develop more slight as the phase of chemotherapy become advance.

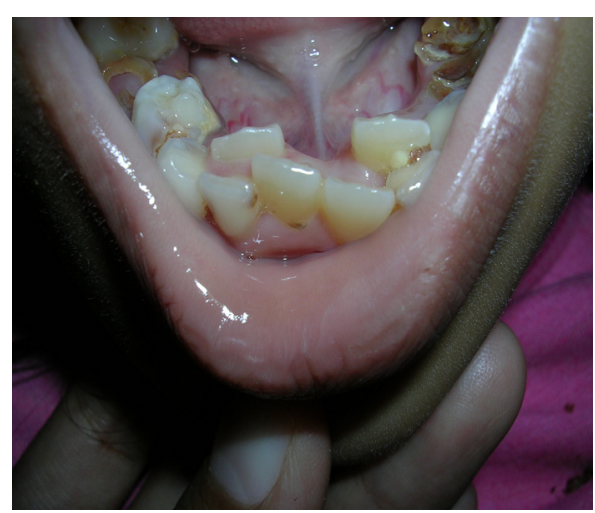

(1)

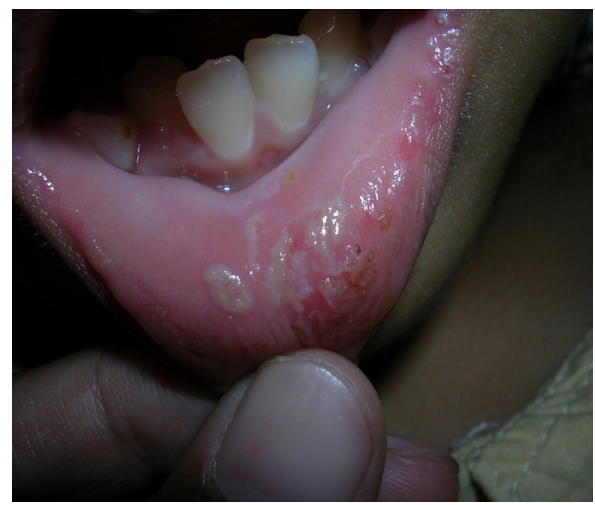

(2)

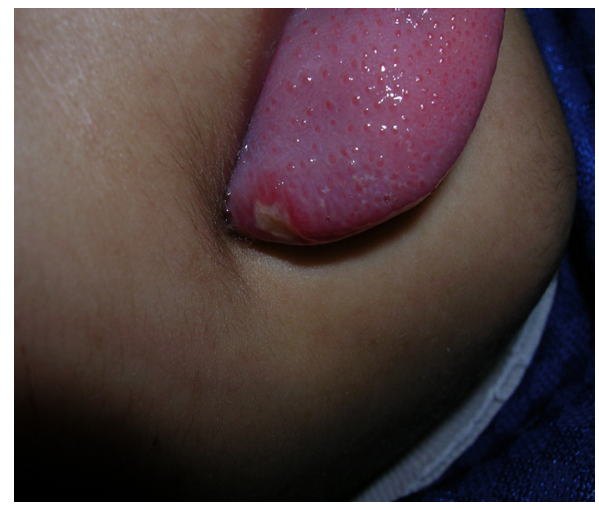

(3)

Figure 1. Mucositis: (1) Scale 1, (2) Scale 2, and (3) Scale 3. 


\section{CONCLUSSION}

Chemotherapy is purposed to treat children who suffer from ALL, but the treatment may induce side effect in the oral mucosa. This side effect is called mucositis. Mucositis developed in the first week after chemotherapy drugs being administered and the severity become slighter as the phase of chemotherapy becomes advanced.

\section{REFERENCES}

1. Pui $\mathrm{CH}$. Acute Lymphoblastic Leukemia. In: Beutler E, Coller BS, editors. Williams hematology. $6^{\text {th }}$ ed. St Louis: Mc Graw Hill; 2001. p. 1141-55.

2. Smith KW. Cancer in childhood, molecular biology and clinical features. In: Practical paediatrics. $4^{\text {th }}$ ed. Philadelphia: Curchill Livingstone Publisher; 1998. p. 512-752.

3. Kostler WJ. Oral mucositis complicating chemotherapy and radiotherapy. Option for prevention and treatment. CA Cancer Clin J 2001:290-315 [cited 2007 Apr 16]. Avalaible from: http://www.cancer.org.

4. Koch G, Poulsen S. Pediatric dentistry, Aclinical approach. Copenhagen: Munksgaard; 2001. p. 421-43.

5. Schubert MM. Measurement of oral tissue damage and mucositis pain. 2001 [cited 2004 Mar 04]. Available from: www. painresearchutah.edu.

6. Carranza FA, Newman. Carranza's clinical periodontology. $9^{\text {th }}$ ed. Massachusetts: W.B. Saunders Co. 2002. p. 214-20.

7. Little JW, Falace DA. Dental management of the medically compromised patient. $6^{\text {th }}$ ed. St. Louis: Mosby Inc.; 2001. p. 365-416.

8. Ramirez-Amador V. Chemotherapy-associated oral mucosal lesions in patient with leucemia or lymphoma. Oral Oncol 1996;32B(5):322-7.

9. Dodan C, Haytac C. Oral health status in children with Acute Lymphoblastic Leukemia and Lymphoma. Turkish J Haemotol 2001; 18(3):179-83.

10. Cho SY. Oral care for children with leukemia. HKMJ 2000 Jun 6 (2):203-8.

11. Miller DR. Hematologic malignancies leukemia and lymphoma. In: Miller DR, Baehner RL, Miller LP, editors. Blood disease in infancy and childhood. $7^{\text {th }}$ ed. St Louis: Mosby; 1995. p. 660-804. 